\title{
¿PODRÁ RESPIRAR SANTIAGO?
}

\section{UNA MIRADA AL NUEVO PLAN DE \\ DESCONTAMINACIÓN ATMOSFÉRICA} Por Mariana Fulgueiras"
Evangelina Dardati***

"Master en Planificación del Desarrollo Urbano UCL y estudiante de MAPPE (UA
**PhD Universidad de Texas en Austin.
El Plan de Descontaminación Atmosférica para la Región Metropolitana, denominado "El Plan de Descontaminacion Atmosterica para lado fino en la Región Metropolitana (RM), conocido como MP 2.5, en vista a su impacto especialmente nocivo para la salud de las personas. El plan se encuentra actualmente en proceso de consulta pública (hasta el 30 de marzo de 2016) y se espera, las primeras medidas comiencen a regir para mediados de este año.

El Plan contiene un extenso listado de medidas que buscan reducir las emisiones generadas por los sectores de transporte, industria, residencial y agricola. Sin lugar a dudas, la que ha generado más controversia es la decisión de expandir la restricción vehicular de caracter permanente a vehiculos con convertidor catalitico de antigüedad mayor a 2012. Las autoridades manifiestan que la medida promoverá el recambio tecnológico de parque automotor, inentivando la compra de vehiculos menos contaninantes.

Algunos citicos plantean que dicha medida, en cambio, incentivarấ la compra de un Otra critica tiene que ver con el cambio de reglas ya que cuando se incorporé la primera generación de restricciones se estableció que estas no afectarian a los vehiculos con sello verde. Finalmente, llama la atención el año de corte seleccionado: 2012 y a este no representa, para vehiculos a gasolina, un cambio tecnológico o de estándares importante que pueda resultar equivalente a lo que significó, en materia de reducción de emisiones, la incorporación de la tecnologia de convertidores catalíticos.

Aparte de estas críticas, otro problema importante que vemos, y que casi no recibió mención en la prensa, es como se realizo el estos comportamientos el Plan sobreestianálisis costo-beneficio del Plan. Este tipo ma los beneficios de la medida.

de análisis es una metodologia que suele utilizarse para tomar decisiones de politica pública, y que consiste en valorar los beneficios y costos de una polltica para luego de de descontaminacion de Santiago presenta dudas si efectivamente se están tomando as decisiones correctas, y/o implementando las politicas adecuadas.

Comenzando por los costos, el plan considera solo a aquellos para implementar las medidas, pero no tiene en cuenta potenciales costos que vendrán aparejados. Por ejemplo, los costos de fiscalización cambios en la productividad de las personas, o el impacto sobre la industria, entre otros.

En cuanto a los beneficios, no se tomaron en consideración de forma explicita los incentivos que la medida generara. Sabemos que los agentes económicos camblan su comportaniento ante cambios estimande que el porcentaje de viajes vehiculos afectos por la restricción no realizarán y por ende descuenta esas emisiones e imputa como beneficio el ahorro en gasolina que significa la reducción. Sin embargo, experiencias anteriores ind can que los incentivos a la población son para adecuar su comportamiento y llevar a cabo los viajes de forma bastante similar a como lo hacen cuando no aplica medida. La poblacion tiene incentivos para salir más temprano de su casa y asi evitar Genaro de restrición y a usar un segundo vehiculo o a no respetar la norm frontar el costo de la sanción correspondiente- Un estudio levado a cabo pata RM en 2010, encontró que si bien las restricciones actuales durante los dias de pre-emergencia afectan al 20\% del parque automotor, la reducción real de viajes en vehiculo particular es únicamente de 5,3\% (De Grange, 2010). Al no contemplar 